\title{
Features of the Fundamentalization of Education in Higher Educational Institutions of Ukraine in the Context of Sustainable Development
}

\author{
Sergii D. Rudyshyn ${ }^{1}$ \\ Volodymyr P. Kravets ${ }^{2}$ \\ Valentyna I. Samilyk ${ }^{1}$ \\ Tetyana V. Sereda ${ }^{1}$ \\ Vitalii O. Havrylin ${ }^{3}$ \\ ${ }^{1}$ Department of Theory and Methods of Teaching Natural Sciences, \\ Hlukhiv Olexander Dovzhenko National Pedagogical University, Hlukhiv, Ukraine \\ ${ }^{2}$ Department of Pedagogic and Educational Management, \\ Ternopil Volodymyr Hnatiuk National Pedagogical University, Ternopil, Ukraine \\ ${ }^{3}$ Department of Combat and Special Physical Training \\ Donetsk Law Institute of the Ministry of Internal Affairs of Ukraine, Kryvyi Rih, Ukraine
}

DOI: https://doi.org/10.36941/jesr-2020-0116

\section{Abstract}

The article outlines peculiarities of the paradigm of fundamentalization of education in pedagogical higher educational institutions (HEIs) of Ukraine on the basis of the concept of sustainable development, namely: 1) performance of three interconnected functions of education - training, education, development; development of students'ability to understand and implement sustainable development strategy in their future professional activity; 2) compliance of the paradigm with modern principles of structuring scientific knowledge, which are based on the internal logic of science, its place and role in the development of civilization in the 21st century; 3) ensuring the integrity of knowledge by integrating it around the core of fundamental scientific concepts; concentrated presentation of the fundamental laws and principles of science from a single methodological position, which allows building bridges between different subjects, without destroying their subject certainty; 4) formation of the theoretical type of scientific thinking of students; creation of intellectual, ethical and cultural foundation for personal self-development; 5) knowledge of modern information and communication technologies; oral and written communication in a foreign language. To acquaint students with the latest scientific achievements of mankind, the teacher must constantly "keep abreast" of socioeconomic and environmental achievements of civilization on the basis of sustainable development, transform them into the content of the subject, as well as develop quality teaching and methodological support for its further understanding by future specialists. Given the rapid reduction of time between the invention and its widespread use, the content of subjects quickly becomes obsolete, which causes the inevitable lag of professional training of students behind the needs of modern society. To trace the synergy of humanization and ecologisation in the context of the fundamentalization of education on the basis of sustainable development, we studied the curricula of a number of pedagogical HEIs of Ukraine, namely: National Pedagogical Dragomanov University, Oleksandr Dovzhenko Hlukhiv National Pedagogical University, Volodymyr Vynnychenko Central Ukrainian Pedagogical University, Rivne State Pedagogical Institute, Ternopil Volodymyr Hnatiuk National Pedagogical University.

Keywords: fundamentalization; sustainable development; science; education; humanitarianization; ecologisation; students; higher educational institutions (HEIs); society 


\section{Introduction}

Today, sustainable development is the goal and the only way to develop humanity, while science and education are effective tools for sound decision-making to achieve it. Interest in the fundamentalization of university education on the basis of sustainable development is determined by the fact that it is the most important direction of updating modern professional education, a means of overcoming its contradictions. The crisis of modern education is a crisis of the educational model, its focus on the utilitarian usefulness of knowledge, on the formation of a man of knowledge, a specialist in his narrow field. This has led to the gradual displacement of humanitarian and humanistic issues from the process of professional education (Budwig, 2015; Evans et al., 2015).

The first thing that comes to mind when reading the literature on this issue is not always clear methodological justification for the interpretation of the process of fundamentalization of education. Traditionally interpreted fundamentalization of education, guided by the "techne" principle, provided only the assimilation of the fundamental laws of science with virtually no holistic vision of the world together with man (Findler et al., 2019; Lozano, 2018).

The mastered laws of science, which remain neutral to the value orientations of students, had no axiological and ethical components necessary in the current social and cultural situation of the globalized world. Therefore, not only the problem of fundamentalization as a problem of a holistic view of the world and, at the same time, deep knowledge of their profession is urgent, but also the problem of axiologisation of modern basic education, related to the internal process of personal selfimprovement, growth of spirituality (Purcell, Beer, \& Southern, 2016; Purcell, Sharp \& Chahine, 2017).

The current situation in education, revealing the limitations of the "techne" principle, showed the relevance of the transition to the "payday" principle as a desire for philosophical reflection on moral and ethical education and culture (Rosenberg, Trencher \& Petersen, 2015). The fact that any weakening of the scientific nature and soundness in education leads to easier public perception of parascientific schemes also adds to the urgency of the problem of fundamentalization of education.

Sustainable development provides a mechanism for the development of society, which is able to meet the current needs of the population without compromising the well-being of future generations. Today, sustainable development is the goal and the unalterable path of human development, while science and education are effective tools for sound approval of decisions to achieve it. This is stated in the final documents of all international conferences of recent decades, organized and held by the UN and UNESCO, namely: Agenda 21 (Decision of the UN World Summits on Sustainable Development, Rio de Janeiro, 1992, Rio+10; Rio+20), The Education 2030 Framework for Action (UNESCO Conference, Paris, 2015). With this in mind, the 2015 Resolution of UN General Assembly outlined the important role of education in transforming society towards sustainability, urged the process of shaping lifestyles in the $21^{\text {st }}$ century based on environmentally sustainable balanced development of the "humanity - the biosphere" system (Korenieva, 2020; UNDP, n.d.).

Promoting the sustainable development of Ukrainian society is the main principle of public policy in the field of higher education. Laws of Ukraine "On Education" (2017), "On Higher Education" (2014), the National Doctrine of Education Development (2002), Ukraine's 2021 National Strategy of Education Development (2013), the New Ukrainian School (2016), the Concept of Development of Pedagogical Education (2018), and other documents of state importance determine the role and place of education in the formation of personality for ensuring sustainable development, outline the main ways of transforming Ukrainian society on the basis of integration of national education for sustainable development in all its parts.

The following factors urge the issue of national Education for Sustainable Development (ESD): 1) Ukraine is integrating into the European educational space, where the issue of ESD is one of the priorities; 2) education plays a multifunctional role in the transformation of society towards sustainable development, and the teacher is the implementer of these functions; 3 ) the training of teachers on the basis of the ESD is recognized by the international community as not fully contributing to the implementation of the UNECE Strategy for ESD and the objectives of the Global Action Program on 
ESD; 4) ESD in Ukraine has not yet taken its rightful place in the training of future teachers (Korenieva, 2020).

The current socio-economic and ecological situation is characterized by the integration of cognitive and value orientations of society, the institution of education and the subjects of educational interaction. Therefore, the fundamentalization of education is understood as a process of assimilation of professional knowledge and skills by students, which is inseparably linked with acquiring broad scientific and philosophical worldview, understanding of universal values. Such orientations involve the formation of a competent, creative, socially responsible personality with a high level of professionalism and focused worldview imperatives of sustainable development. In other words, the ideas and principles of sustainable development must become a priority in education in general. These tendencies are reflected in certain features of the fundamentalization of education in HEIs of Ukraine.

As science seeks new knowledge and education popularises it, the attitude of educators to the concept of "fundamental science" is gradually changing, it loses its exceptional appeal (despite the great successes of particle physics or molecular genetics, etc.). It is no longer enough to discover the basic laws and understand how the world works "in principle". This is because the exact fundamental laws that describe the functioning of systems, operate in the real world, and any nonlinear process leads to a bifurcation at a bifurcation point, where the system can synergistically choose one path or the other. We deal with the choice of decisions, where their consequences are impossible to predict, because each of these decisions is characterized by amplification, the slightest inaccuracies are exaggerated and have far-reaching consequences. Every single moment the causal connection is preserved, but it is no longer visible after several bifurcations. Sooner or later, the initial information about the state of the system ceases to be useful (Kilova, 2009). Thus, the need to take into account the synergetic phenomenon in educational or managerial decisions is obvious, because: 1) the future (attractor) determines the vector of development of the present; 2) society has chosen an attractor sustainable development - at the bifurcation point of modern socio-economic and environmental crisis.

Other scholars consider, from the perspective of a system approach, the fundamentality of education as a system characterized by the integrity, interconnection, and interaction of elements, as well as the system-forming rods. That is, the fundamentalization of pedagogical education is defined as the principle of bringing fundamental knowledge to priority positions, and providing this knowledge with the basis or core of knowledge accumulation, and the formation of skills based on their basis. Fundamentality of education in HEIs directs the content of education to methodologically important, invariant elements of human knowledge and culture, promoting the initiation, development and realization of creative potential of students, provide a qualitatively new level of their internal intellectual, emotional, and moral culture, create internal need for self-development and self-education throughout life, contribute to the adaptation of an individual in changing socio-economic, technological, and environmental conditions (Scholz \& Steiner, 2015; Brudermann et al., 2017).

In addition, researchers define the fundamentalization of education as the focus of education on the creation of holistic generalising knowledge, which would be the core (basis) of all knowledge acquired by the student, would combine knowledge obtained in the learning process into a single worldview system based on modern methodology (Passey, 2019; Lai \& Peng, 2020).

At the same time, some modern scholars emphasize that the fundamentalization of education in HEIs is aimed at mastering the most essential and stable knowledge that underlies the model of the scientific picture of the modern world, forming the ability to think systemically, creatively, critically, build professional activities (Szkornik, 2017; Lee, Watson \& Watson, 2020).

We share the views of the authors (Orozco-Messana, de la Poza-Plaza \& Calabuig-Moreno, 2020), who consider the fundamentality of knowledge as their reliability, strength, stability, soundness. We also believe that education becomes fundamental when it aims at identification of deep essential connections between various processes of the surrounding world on the basis of modern consensus scientific knowledge.

The approach that fundamental knowledge is core, system-forming, methodologically significant 
ideas (Kurilovas \& Kubilinskiene, 2020) is striking. Fundamental knowledge combines, "folds" different aspects of the object of study into certain images, concepts, laws, which in each case can be instantly "unfolded", effectively used to solve specific problems (Hernandez, Vargas \& Paucar-Cáceres, 2018; Siraj-Blatchford \& Pramling-Samuelsson, 2016).

The following view is worth noticing: the fundamental knowledge, in contrast to applied knowledge, rules, algorithms, and technologies of specialized professional activities, which have conjunctural and informational value throughout the working life of the specialist and are the basis for generating new knowledge implemented in practice (Viegas et al., 2016; Barth \& Michelsen, 2013) (Figure 1).

Currently, the process of enriching the fundamental sciences with new information is extremely fast, which is conditionally reflected by the dependence $\psi(t)$ in Figure 1 (curve I). However, not all promising theoretical achievements are instantly applied in practice (i.e., direct production of goods and services): the interval $a_{1}-a_{2}$ reflects the gap between production and science at time $t_{1}$. The curves in Figure 1 are rather conditional - they reflect the main thing only on average in the relationship between fundamental science, industrial practice and higher education. Curves II and III meet at those points that correspond to the cases of practical implementation of conceptual developments made in a certain HEI (point $A$ ) - such an institution has the opportunity to keep up with the production in the coverage of students' own developments. Curves II and I occur at points that correspond to cases of "instantaneous" implementation of the results of fundamental research (point $B$ ) - such studies are usually commissioned. We note a special importance of point $C$, which reflects the process of implementation of the results of fundamental research in the educational process, and point $D$, which characterizes the conduct of fundamental research in the research center of a particular HEI.

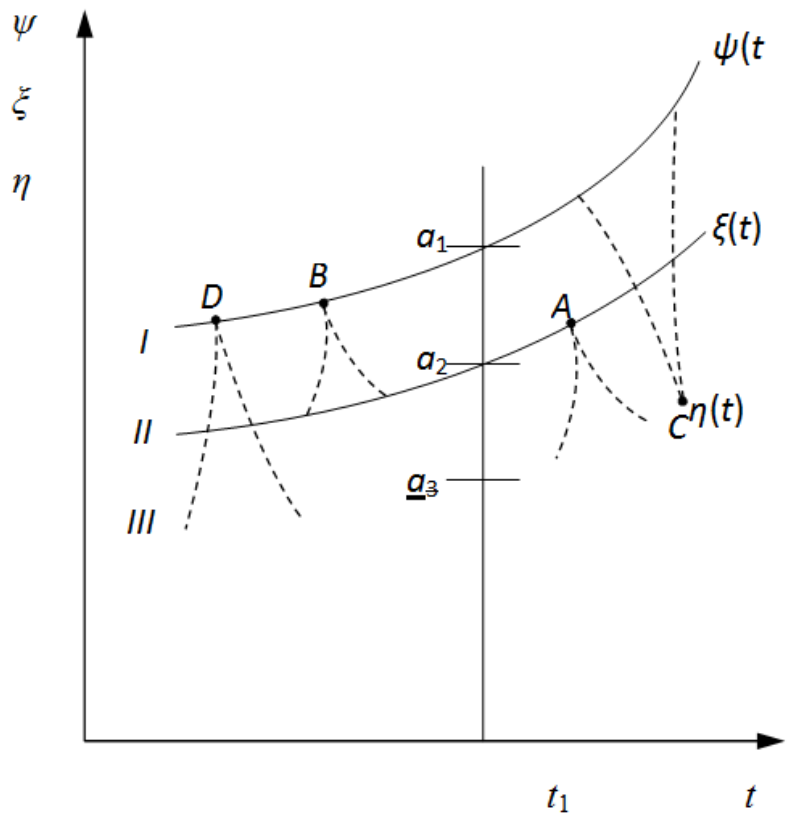

Figure 1. The scheme of reflection of the process of growth of information volume within the basic sciences $\psi(t)(I)$, innovations in production $\xi(t)(I I)$, and updating the content of educational material in HEIs of Ukraine $\eta(t)(I I I)$

Source: Semerikov and Teplytskyi (2009) 
Based on the obtained generalizations, we note that currently the fundamentalization of professional education in different HEIs of Ukraine is characterized by specific factors dictated by: a) the autonomy of HEIs in the choice of educational programs, content of curricula; b) qualification of the teaching staff.

Studying and summarising different views of scholars and practitioners on the essence of fundamentalization of education, we came to the conclusion that the concept of "fundamentalization of higher professional education in the context of sustainable development" should be interpreted as the formation of a holistic meta-knowledge of professional activity, which is the "genetic" basis for the generation of relevant practice-oriented knowledge implemented in real practice, providing selfdevelopment of the subject in proportion to changing personal and social needs based on sustainable development.

\section{Materials and Research Methods}

The idea of research was to compare the curricula of different pedagogical HEIs of Ukraine from the point of view of stating the ideological and theoretical orientation of the fundamentalization of education. The experiment involved the curricula of the first level of higher education for Speciality 014: Secondary Education (Mathematics), additional Specialty 014: Secondary Education (Information Science) in the field of knowledge or:Education/Pedagogy. This decision is dictated by the current trend towards professional education on the basis of sustainable development.

We studied the curricula of five HEIs of Ukraine, namely: National Pedagogical Dragomanov University, Oleksandr Dovzhenko Hlukhiv National Pedagogical University, Volodymyr Vynnychenko Central Ukrainian Pedagogical University, Rivne State Pedagogical Institute, Ternopil Volodymyr Hnatiuk National Pedagogical University for 2015 (TNPU 2015) and 2017 (KR99).

\section{Results}

To date, there is no single definition of "fundamentalization", but this phenomenon indicates the existence of a certain foundation (from the Latin fundamentum - the basis), i.e. the base, the foundation, the main, essential, underlying thing." The name "fundamental", as an adjective to the foundation, is based on the existence of some main, solid, reliable, and deep foundation, made for a long time, and is a qualitative characteristic of any phenomenon or process, takes into account all elements, comprehensively covers and carefully conveys the content of something. Philosophy recognizes the belief in the existence of fundamentalism as an unchanging fundamental basis of reality, which is revealed through the only correct qualitative criteria to distinguish reality from appearance, truth from mistake, and so on. In essence, the concept of "fundamentalism" is interpreted as permissible limit principles that form for cognitive diversity an inviolable monolith, the center-base, where the units of knowledge derive from. In general, scholars consider the category of "fundamentalization" as a significant improvement in the quality of education and educational level of specialists through proper scientific updating of its content of academic subjects and replacement of methodological approaches to the educational process.

Fundamentalization is often replaced by the integration of knowledge of humanities and natural sciences, increased theoreticality, inclusion of the latest scientific achievements in the content of teaching the subject, increasing in-class time for general scientific training, mathematization of education, etc. However, these features characterise only some areas of fundamentalization of professional university education. In the context of the article and in our understanding, the category "fundamentalization of education in HEIs of Ukraine in the context of sustainable development" belongs to the methodological categories because it gives preference to:

- the main goals and core ideas of sustainable development, which direct professional education to scientific and educational support of society's transition to sustainable 
development;

- the importance of the content of general theoretical subjects, universal and synergetic methods of cognition, which together lay the foundation for the interpenetration of system effective knowledge in the educational process, allow building bridges between different subjects without destroying their subject certainty;

- system knowledge, universal concept, ability to standardise scientific and educational material, practical skills of effective implementation of knowledge, features of scientific worldview, actualized thinking, ability to work in a team and act in compliance with moral and ethical norms;

- the ability of abstract thinking, analysis and synthesis of information based on scientifically reliable facts and logical arguments using various sources; knowledge of modern information and communication technologies; oral and written communication in a foreign language;

- conducting research at the modern scientific level, and the ability to theoretically and practically use their results.

Understanding the traditions and trends of fundamentalization of education, the peculiarities of this process at the present stage of the development of society allows improving the system of training future specialists taking into account the new requirements of life, without giving up the positive and valuable things that have been accumulated by Ukrainian education. The current reality is that the formed knowledge of graduates is often unclaimed due to the high rate of change of socio-economic, information, technological, and environmental conditions. Therefore, education should be aimed at providing graduates with invariant knowledge so that they can easily adapt to new conditions, continue self-education throughout life. This is possible through the fundamentalization of education (BentonShort \& Merrigan, 2016; Howlett, Ferreira \& Blomfield, 2016).

The analysis of the curricula of the first level of higher education for Speciality 014: Secondary Education (Mathematics), additional Specialty 014: Secondary Education (Information Science) in the field of knowledge or:Education/Pedagogy at National Pedagogical Dragomanov University (NPU), Oleksandr Dovzhenko Hlukhiv National Pedagogical University (HNPU), Volodymyr Vynnychenko Central Ukrainian Pedagogical University (KSPU), Rivne State Pedagogical Institute (RSPI), Ternopil Volodymyr Hnatiuk National Pedagogical University for 2015 (TNPU 2015) and 2017 testified that the content of education as a pedagogically adapted social experience of mankind, identical to human culture, should include not only knowledge and experience of reproductive and productive activities, but also experience of creative activity, as well as experience of emotionally valuable and sustainable relations. Such personality traits as the ability to self-education and creativity is an important characteristic of the fundamentalization of education on the basis of sustainable development.

The concept of sustainable development implies that basic education should be based on the organic unity of natural science and the humanities. The relationship of the content of academic subjects is necessary to create a holistic scientific picture of the world, which is the basis for further practical activities of the student, allows us to understand the laws of nature and society, which guide the humanity and cannot be ignored (Karlusch, Sachsenhofer \& Reinsberger, 2018).

We support the point of view of scholars and practitioners on the orientation of modern education on the development of soft skills in students (communicativeness, oral and written communication in a foreign language, tolerance, humanity, ability to act in compliance with moral and ethical norms). Consistent and successful self-education throughout life is possible only on the basis of the synergy of cognitive and general cultural content of education. It is reasonable to talk here about the inseparable connection of moral, axiological, information, technological, pragmatic, and activity aspects at each stage of education (bachelor, master, $\mathrm{PhD}$ ).

Currently, higher education actualizes the humanistic paradigm, which is based on the theoretical provisions of humane pedagogy, methodology of humanitarian knowledge, which provides for the content and organization of the educational process based on personality-oriented education (subject-subject relations of teacher and student); appeal to an individual's personal experience, his 
inner state, situations of human existence; moral and value dominant of the worldview.

From the standpoint of the activity approach, which considers learning as an activity, the fundamentality of modern education in HEIs of Ukraine is represented by the following structural elements in learning outcomes: experience of cognitive activity fixed in the form of knowledge; ability to properly perform certain actions based on the appropriate use of acquired knowledge and skills; ability to be creative in solving problems - willingness to find non-standard solutions; ability of emotional and value communications, etc. In this case, each element corresponds to the principle of systematization in learning, involves awareness of the structural links between the elements of educational material.

From the point of view of the system approach, the fundamentality of higher education of Ukraine through the prism of the principles of sustainable development is characterized by integrity, interconnection and interaction of elements, and also existence of system-forming cores, universal concepts. In particular, the content of education is grouped around the most important concepts that have universal significance for all sciences, including: sustainable development, energy, mass, motion, entropy, space/time, model, system, order-chaos, randomness, symmetry, information, evolution, the relationship between the structure and properties of the object, DNA, animate/inanimate, biosphere, biodiversity, noosphere, etc. The main purpose of this approach is to build a single natural-science picture of the world, because nature is not divided into physics, chemistry, biology, geography, it is unique.

Universal concepts are considered as a single coordinate system in which any natural object or process is located. The teacher must know a narrative - talk simply about the complex things. For this purpose, teachers master the scientific style of thinking, understanding the ways of activity that allow to understand the scientific foundations of modern production and interact with the environment. The integrity of the model of natural-science picture of the world is the result of the emergent manifestation of the relationship between its elements at all levels of the organization of matter.

\section{Discussion}

Fundamentalization of education in HEIs of Ukraine on the basis of sustainable development relies on the fact that in the learning process it is necessary to form a holistic natural-science, socio-economic and moral values of students, teach them to think globally (through holistic fundamental laws and theories), and act locally to solve specific socio-economic and environmental problems in practice. To do this, students should get acquainted and understand that a holistic program of sustainable development contains 17 goals that the world must achieve by 2030, including: overcome poverty and hunger all over the world; ensure the maintenance of health and the promotion of a healthy lifestyle for all people; ensure comprehensive and equitable access to quality education and expand opportunities for lifelong learning; achieve gender equality; ensure the availability of water and water treatment, as well as the possibility of using affordable, reliable, safe and sustainable energy for all residents; stimulate sustainable and comprehensive economic growth, full and productive employment, as well as decent working conditions; make cities and other settlements comfortable, safe, sustainable and environmentally friendly; take immediate action to adapt to climate change and its consequences; preserve, restore and promote the sustainable use of aquatic and terrestrial ecosystems, stop the loss of biodiversity, etc.

The principle of the integrity of education means that it is necessary to study not isolated didactic units, but coordinated sections of subjects, taking into account interdisciplinary relationships. Intradisciplinary relationships usually reveal the relationship of the basic concepts of the studied field of knowledge, its structure. Therefore, we can argue that the formation and development of ideas about the concept and structure of the subject is a condition for the implementation of intradisciplinary relationships in the study of this subject. Interdisciplinary relationships are expressed in the formation of a holistic view of students about the model of the modern scientific picture of the world. This creates an objective basis for the construction of the educational process, when it becomes possible to integrate 
different content and methodological aspects in the process of forming theoretical knowledge and practical skills (Rouxle \& Pretorius, 2016; Trencher, Terada \& Yarime, 2015).

Education is expected to develop the students' holistic thinking that relies on identification and understanding of the ways the processes work and how they are interconnected to form the world. The above leads to fundamentalization of education, which is seen as a system to have been developed to comply with the principles of sustainable development. The fundamental knowledge of students changes relatively slowly, and retains its significance during the average period of the employment history, as well as provide an opportunity to independently form new knowledge and skills (United Nations General Assembly, 2015).

Fundamentalization of education for sustainable development organically encompasses the ecologisation of education, which we interpret as the process of saturation of educational programs for training specialists in all specialties with environmental requirements - understanding the causal relationships between human activities and its environmental consequences; as an actualisation of the three components of education for sustainable development, aimed at: 1) economic development; 2) socio-cultural development; 3) environmental protection and environmentally friendly activities. To this end, the mandatory subject Fundamentals of Ecology is introduced into the curricula for all specialties, environmental topics are integrated into the content of other educational components (academic subjects, internships, term papers, diploma projects), and elective subjects are offered (Socioecology, Fundamentals of Environmental Culture, Environmental Security Strategy: Integration of European Experience).

We believe that scientific, philosophical, historical, artistic sources and tools, universal values, national traditions contribute to the humanization and ecologisation of education, which together cover global (noosphere) thinking, the formation of moral and value orientations with their subsequent actualization in professional and social activities.

The analysis of the curricula selected for the experimental study of HEIs allowed establishing the differences in the segment of blocks of professional subjects and subjects of specialization (from $4.5 \%$ to $20 \%$ ) in the curricula of the first level of higher education for Speciality o14: Secondary Education (Mathematics), additional Specialty 014: Secondary Education (Information Science) in the field of knowledge or: Education/Pedagogy (Figure 2). We believe that this is not the only reason for the different level of professional training of graduates who studied in one specialty, but also significantly complicates the transfer of a student from one HEI to another.

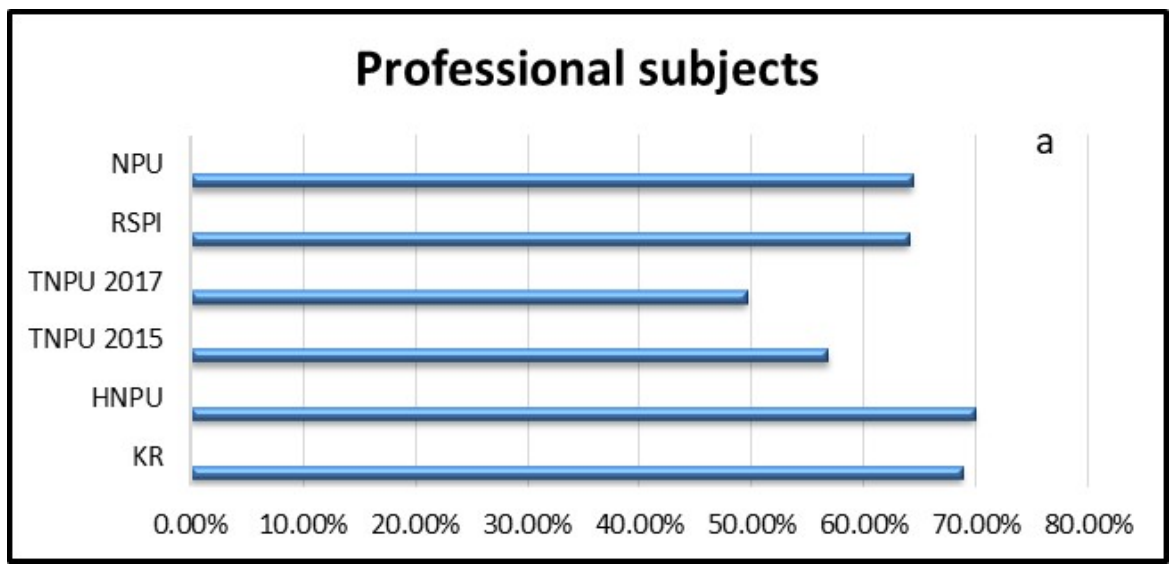




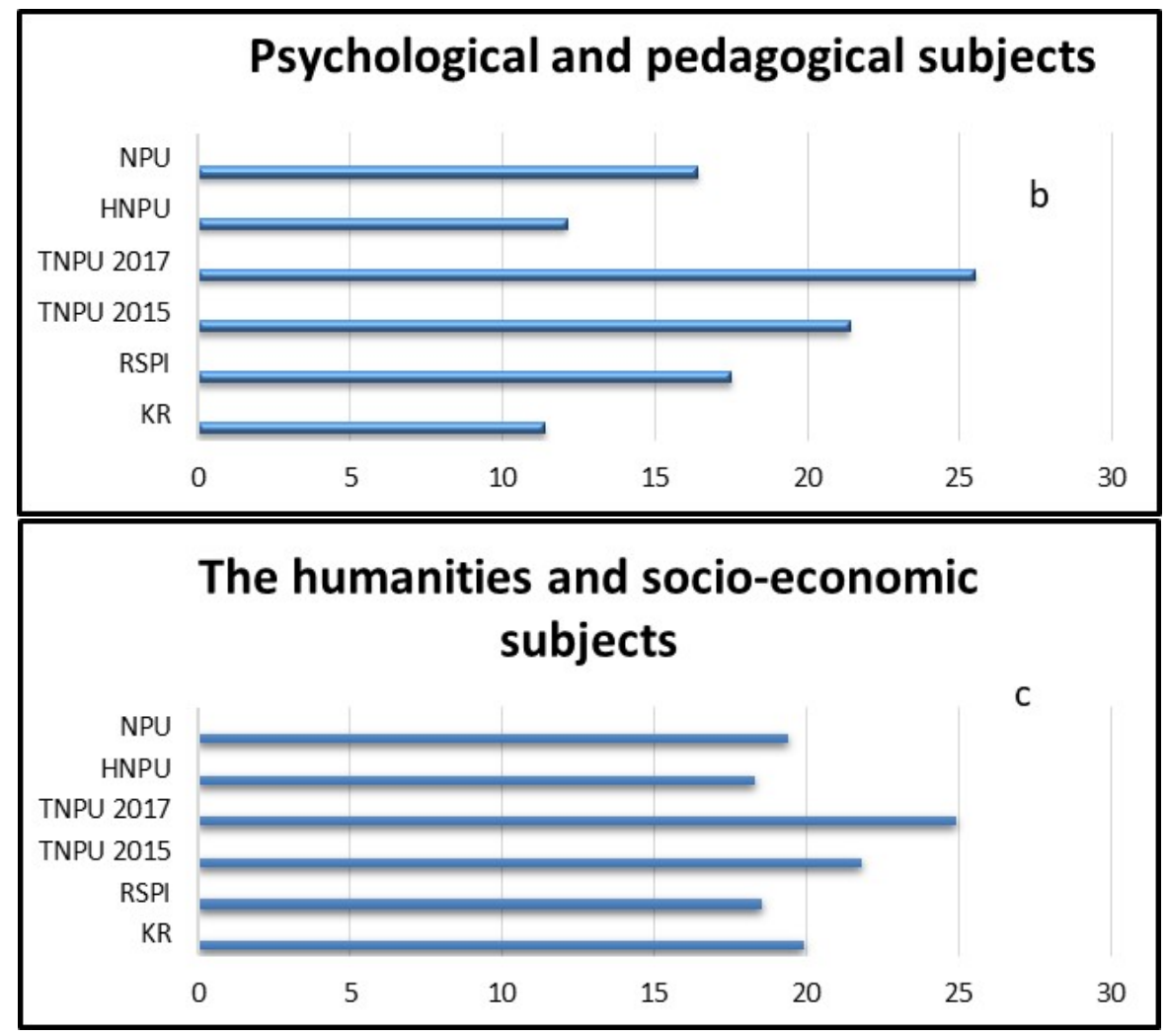

Figure 2. Share of blocks in curricula of Speciality o14: Secondary Education (Mathematics), additional Specialty 014: Secondary Education (Information Science) in the field of knowledge o1: Education/Pedagogy: $a$ - professional subjects and subjects of specialization; $b$ - psychological and pedagogical subjects; $c$ - the humanities and socio-economic subjects

The academic subjects' curriculums used in HEIs of Ukraine are designed to cover relevant theoretical concepts. The learning outcomes are detailed in the competencies that are supposed to be acquired by the student after the course has been completed. The content of the subject is delivered in a stage-wise manner based on gradually increasing complexity of the concepts. However, this approach has nothing in common with creating new knowledge. The above implies that primary attention should be paid to general and fundamental concepts delivered first (Boron, Murray, \& Thomson, 2017). The basic concepts play the role of "generators" of knowledge in the training course, which is the basis of fundamentalization. They contribute to both students' theoretical awareness and course effectiveness because these create the structured learning environment that helps the students gain new learning experience, build up knowledge, and structure, and apply it in the mock settings. Thus, the education in Ukraine can be upgraded through application of the sustainable development principles. In this regard, the fundamentalization of education is seen as an output of training individuals who are capable of core and system-forming knowledge to independently find and make responsible decisions in uncertainty, in critical stressful situations when a person faces new, complex environmental and social challenges. These can be possible due to the students' abilities to practically apply the theoretical knowledge which is seen as a key outcome of the learning process involving the competency-based approach. The approach pursues the triune goal of raising students' theoretical awareness, practical 
applicability of theoretical knowledge and development of personal qualities such as general and professional competencies that provide the ability and willingness to apply the formed knowledge, skills and abilities in practice (competence). The competence-based approach to learning raises the issue of the graduates' readiness to apply their knowledge in their activities to a new methodological level (Caniglia et al., 2018). Among the competencies, we pay special attention to the following: the ability to understand and implement the strategy of sustainable development of mankind in the process of professional activity; the ability to exercise their rights and responsibilities as members of society, realize the values of civil (free democratic) society, the rule of law, human rights and freedoms as well as the rights and freedoms of the citizens of Ukraine; ability to work in a team and act in compliance with moral and ethical norms; knowledge of modern information and communication technologies; oral and written communication in a foreign language; conducting research at the modern scientific level and the ability of theoretical and practical use of their results.

The humanistic and ecological components of the fundamentalization of education in HEIs of Ukraine in the context of sustainable development are aimed at the formation of:

- universal and invariant (in terms of technology, specific details, people's opinions, etc.) elements of culture and environmentally friendly behaviour of an individual, providing a qualitatively new level of creative, intellectual, emotional, moral and environmental culture, contributing to personal adaptation in changing socio-economic-environment, as well as information and technological conditions of the globalised world;

- emergently holistic and diverse humanitarian and natural science worldview for understanding the laws of nature and society, creating a single worldview system based on the fundamental principles of modern methodology (philosophical, general, specifically scientific and methodological);

- optimal intellectual environment for the formation of generalized ways of thinking and acting, the ability to think globally and act locally to enrich one's inner world of the future specialist, form the inner need for self-development and self-education throughout life;

- the ability to interact with the information environment, where the educational and cognitive activities are filled with personal content;

- readiness of students to apply their knowledge and skills in both standard and non-standard situations.

Thus, the process of fundamentalization of education in pedagogical HEIs of Ukraine on the basis of sustainable development concerns various spheres of training of future teachers. The quality of their professional training depends on the quality of training of the younger generation, future specialists in any field. It is necessary to further improve the quality of fundamental training in subject areas, in the theory and methods of teaching that will ensure the readiness of teachers for providing scientific and educational support of sustainable development of society.

In such conditions, the fundamentalization of education on the basis of sustainable development helps to bridge the historically formed gap between the humanities and natural sciences, which leads to a holistic image of the relationship between nature and society, knowledge and culture. The implementation of this paradigm will allow the student, if necessary, to change the speciality, orientation of education, which, in turn, may cause increased interest in the educational components of the curriculum being studied and, accordingly, the desire for their deeper learning.

It is possible to understand the need for changes in the educational system of HEIs of Ukraine if we compare the paradigm of fundamentalization of education with the principles and goals of sustainable development. We can see that humanity has turned most of the biosphere into a technosphere, which actualizes the environmentally friendly model of sustainable coevolutionary development of the "society-biosphere" system, while science and education are effective tools for sound decision-making to achieve it.

In our opinion, the sense of the concept of fundamentalization of education for sustainable development is "overcoming the past." This process should not be understood as a rejection or denial 
of the past, but as a way to enter the new world socio-economic-ecological reality through the use and rethinking of the role and place of biopsychosocial being (man) on the planet. The fact is that man is the only creature on the planet that generates garbage (pollutes the environment, destroys its own ecological niche).Therefore, humanitarisation and ecologisation is a reflection on the socio-ecological realities of today, which determines a person as a self-sufficient, creative and responsible individual who understands his physical dependence on the state of the environment. Fundamentalization of pedagogical education on the basis of sustainable development contributes to the formation in future teachers of a dynamic combination of knowledge, skills, ways of thinking, professional, ideological and civic qualities, motives and values, which together determine the ability to perform educational functions for sustainable development in professional and social activities.

\section{Conclusions}

Sustainable development is a new worldview synergetic paradigm of human self-organization within the biosphere, when modern globalised society chooses an attractor at the point of bifurcation of its own crisis state - balanced socio-economic and ecological development. Fundamentalization of education in HEIs promotes such development and provides the fulfilment of a number of objectives:

1) Carries out three interconnected functions of education - training, education, development; allows creating a foundation for the accumulation of fundamental knowledge based on a single methodology. This creates a prerequisite for the implementation of the process of selfeducation of a specialist throughout life. Through this process the graduate of HEI will be able to navigate in modern socio-economic and environmental conditions and, if necessary, change specialty/study in another educational program.

2) Ensures the integrity of knowledge by integrating it around the core of fundamental scientific notions, concepts, theories; concentrated presentation of the fundamental laws and principles of science from a single methodological position, which allows building bridges between different subjects without destroying their disciplinary certainty.

3) Contributes to the formation of the theoretical type of scientific thinking of students, creating an intellectual, ethical and cultural foundation for personal self-development.

4) Requires knowledge of modern information and communication technologies, oral and written communication in a foreign language.

Thus, education for sustainable development formulates new goals, expands the content, changes the traditional forms of higher education; its scientific foundations are just emerging, but it is already clear that it is systemic in nature and should extend to all specialities and levels of education.

\section{Prospects for Further Scientific Research}

The conducted research does not cover all the problems of ensuring the fundamentalization of education in HEIs of Ukraine on the basis of sustainable development. Scientific research is limited to the specific conditions of the study (covers only the training of future teachers of Mathematics and Computer Science in 7 pedagogical HEIs), and the research position of the authors. Our research can be continued and extended to the training of specialists in other specialties, as there is an urgent need to develop educational and methodological support for the fundamentalization of education on the basis of sustainable development.

Prospects for further research can be the following:

- organization of monitoring of observing the principles of fundamentalization in different HEIs of Ukraine; research of content and procedural features of fundamental training of future specialists of other specialties;

- study of these features at the second level of higher education (master's degree) and PhD. 


\section{References}

Barth, M.; \& Michelsen, G. (2013). Learning for change: An educational contribution to sustainability science. Sustainability Science, 8(1), 103-119. https://doi.org/10.1007/s11625-012-0181-5

Benton-Short, L., \& Merrigan, K. A. (2016). Beyond interdisciplinary: How sustainability creates opportunities for pan-university efforts. Journal of Environmental Studies and Sciences, 6, 387-398. https://doi.org/10.1007/s13412-015-0341-x

Boron, S., Murray, K. R., \& Thomson, G. B. (2017). 'Sustainability education: towards total sustainability management teaching'. In: W. L. Filho, L. Brandli, P. Castro, \& J. Newman (Eds.), Handbook of theory and practice of sustainable development in higher education, vol. 1 (pp. 37-52). Cham: Springer. https://doi.org/10.1007/978-3319-47868-5

Brudermann, T., Holländer, R., Pastres, R., Posch, A., \& Schot, P. (2017). Integrating Interdisciplinarity and Internationality in Sustainable Development Education. GAIA-Ecological Perspectives for Science and Society, 26(4), 360-362.

Budwig, N. (2015). Concepts and tools from the learning sciences for linking research, teaching and practice around sustainability issues. Current Opinion in Environmental Sustainability, 16, 99-104. https://doi.org/10.1016/j.cosust.2015.08.003.

Caniglia, G., John, B., Bellina, L., Lang, D. J., Wiek, A., Cohmer, S., \& Laubichler, M. D. (2018). The glocal curriculum: a model for transnational collaboration in higher education for sustainable development. Journal of Cleaner Production, 171, 368-376. https://doi.org/10.1016/j.jclepro.2017.09.207

Evans, J., Jones, R., Karvonen, A., Millard, L., \& Wendler, J. (2015). Living labs and co-production: University campuses as platforms for sustainability science. Current Opinion in Environmental Sustainability, 16, 1-6. https://doi.org/10.1016/j.cosust.2015.06.005

Findler, F., Schönherr, N., Lozano, R., Reider, D. \& Martinuzzi, A. (2019). The impacts of higher education institutions on sustainable development. International Journal of Sustainability in Higher Education, 20(1), 2338. https://doi.org/10.1108/IJSHE-07-2017-0114

Hernandez, P. M., Vargas, V., \& Paucar-Cáceres, A. (2018). ‘Education for sustainable development: an exploratory survey of a sample of Latin American higher education institutions'. In: Implementing sustainability in the curriculum of universities (pp 137-154). Cham: Springer.

Howlett, C., Ferreira, J.-A., \& Blomfield, J. (2016). Teaching sustainable development in higher education. Journal of Sustainability in Higher Education, 17(3), 305-321.

Karlusch, A., Sachsenhofer, W., \& Reinsberger, K. (2018). Educating for the development of sustainable business models: Designing and delivering a course to foster creativity. Journal of Cleaner Production, 179, 169-179.

Kilova, H. O. (2009). Transformation of the philosophical paradigm of education in the context of the Bologna Declarations [PhD thesis]. National Pedagogical Dragomanov University, Kyiv, Ukraine.

Korenieva I. M. (2020). Theoretical and methodical bases of preparation of future teachers of biology for realization of functions of education for sustainable development [PhD thesis]. Hlukhiv National Pedagogical Oleksandr Dovzhenko University, Hlukhiv,Ukraine.

Kurilovas, E. \& Kubilinskiene, S. (2020). Lithuanian case study on evaluating suitability, acceptance and use of IT tools by students-An example of applying Technology Enhanced Learning Research methods in Higher Education. Computers in Human Behavior, 107, 106274. https://doi.org/10.1016/j.chb.2020.106274

Lai, Y.-C. \& Peng, L.-H. (2020). Effective Teaching and Activities of Excellent Teachers for the Sustainable Development of Higher Design Education. Sustainability, 12(1), 28. https://doi.org/ 10.339o/su12010028

Lee, D., Watson, S. L., \& Watson, W. R. (2020). The Relationships Between Self-Efficacy, Task Value, and SelfRegulated Learning Strategies in Massive Open Online Courses. The International Review of Research in Open and Distributed Learning, 21(1), 23-39. https://doi.org/10.19173/irrodl.v2oi5.4389

Lozano, R. (2018). Proposing a definition and a framework of organizational sustainability: a review of efforts and a survey of approaches to change. Sustainability, 10(4), 11-57.

Orozco-Messana, J., de la Poza-Plaza, E., \& Calabuig-Moreno, R. (2020). Experiences in Transdisciplinary Education for the Sustainable Development of the Built Environment, the ISAlab Workshop. Sustainability, 12(3), 1143. https://doi.org/10.339o/su12031143

Passey, D. (2019). Technology-enhanced learning: Rethinking the term, the concept and its theoretical background. British Journal of Educational Technology, 50, 972-978. https://doi.org/10.1111/bjet.12783

Purcell, W. M., Sharp, L., \& Chahine, T. (2017). 'New governance models for entrepreneurial universities: a conceptual framework'. Academic Proceedings of the 2017 University-Industry Engagement Conference: From Best Practice to Next Practice - Asia-Pacific Opportunities and Perspectives, 19-29. 
Purcell, W.M., Beer, J., \& Southern, R. (2016). Differentiation of English universities: the impact of policy reforms in driving a more diverse higher education landscape. Perspectives: Policy and Practice in Higher Education, 20(1), 24-33. https://doi.org/10.1080/13603108.2015.1062059

Rosenberg, D., Trencher, G., \& Petersen, J. (2015). Students as change agents in a town-wide sustainability transformation: the Oberlin project at Oberlin college. Current Opinion in Environmental Sustainability, 16, 14-21. https://doi.org/10.1016/j.cosust.2015.07.005

Rouxle, C., \& Pretorius, M. (2016). Conceptualizing the limiting issues inhibiting sustainability embeddedness. Sustainability. 8(364), 1-22. https://doi.org/10.3390/su8040364

Scholz, R. W., \& Steiner, G. (2015). Transdisciplinarity at the crossroads. Sustainability Science, $10,521-526$. https://doi.org/10.1007/s11625-015-0338-o

Semerikov, S. O., \& Teplytskyi, I. O. (2009). Fundamentalization as a Basis for the Development of Innovative Higher Education. Collection of Scientific Papers of Kamianets-Podilsk National Ivan Ogienko University: Pedagogical Series, 15, 249-251. https://doi.org/10.32626/2307-4507.2009-15.249-251

Siraj-Blatchford, J. \& Pramling-Samuelsson, I. (2016). 'Education for sustainable development in early childhood care and education: an introduction'. In J. Siraj-Blatchford, C. Mogharreban, \& E. Park (Eds.), International research on education for sustainable development in early childhood (pp. 1-15). Cham: Springer.

Szkornik, K. (2017). Teaching and learning on a transnational education programme: Opportunities and challenges for flying faculty in Geography and related disciplines. Journal of Geography in Higher Education, 41(4), 521531. https://doi.org/10.1080/03098265.2017.1337735

Trencher, G., Terada, T., \& Yarime, M. (2015). Student participation in the co-creation of knowledge and social experiments for advancing sustainability: experiences from the University of Tokyo. Current Opinion in Environmental Sustainability, 16, 56-63. https://doi.org/10.1016/j.cosust.2015.08.001

UNDP. (n.d.). Sustainable Development Goals. Retrieved from https://www.ua.undp.org/content/ukraine /uk/home/ourwork/sdg-overview.html

United Nations General Assembly. (2015). Transforming our world: the 2030 agenda for sustainable development. Retrieved from www.un.org/ga/search/view_doc.asp?symbol=A/RES/70/1\&Lang=E

Viegas, C. V., Bond, A. J., Vaz, C. R., Borchardt, M., Pereira, G. M., Selig, P. M., \& Varvakis, G. (2016). Critical attributes of Sustainability in Higher Education. A categorisation from literature review. Journal of Cleaner Production, 126, 260-276. 